\title{
DOIS ESTUDOS (LEGÍTIMOS) DE LITERATURA COMPARADA
}

Márcia Maria de Arruda Franco

Universidade Federal de Ouro Preto

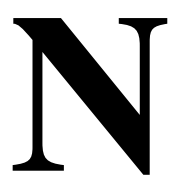

o Congresso da Associação Brasileira de Literatura Comparada, realizado em 1996, no Rio de Janeiro, Luiz Costa Lima chamava a atenção para a necessidade de se legitimar os estudos comparativos, sob pena de estes submergirem num vale-tudo indiscriminado. Na mesma mesaredonda, Leyla Perrone-Moisés alertava contra o perigo dos "Estudos Culturais", pois poderiam "junto com a água do banho, jogar fora a criança", isto é, perder a especificidade do discurso poético. Uma via legítima para os estudos comparativos é a reinterpretação que os autores renascentistas fizeram não só dos modelos poéticos greco-latinos, mas também da herança trovadoresca. A partir da releitura de uma lenda greco-latina por alguns quinhentistas ibéricos e a partir da circulação de ritmo e imagem medievais na poesia renascentista de Sá de Miranda, o presente trabalho compara textos de períodos histórico-literários distintos, sem deixar de lado nem o texto poético nem a história literária.

\section{1 - A lenda de Leandro e Hero - do epigrama latino às versões renascentistas ibéricas}

A nova poesia do Renascimento se caracteriza pela imitação de temas clássicos. Entre os poetas peninsulares a lenda de Leandro e Hero parece ser a de maior fortuna. Mesmo em cantares velhos, em que o assunto clássico ou bíblico é raro, 
encontra-se um pequeno ciclo de Hero e Leandro. ${ }^{1}$ D. Carolina salienta que o "lindo conto de Hero e Leandro" foi "tratado com predileção pelos quinhentistas peninsulares” (Ibidem).

Faria e Sousa comenta: "Muchos son los escritores que se emplearon en este argumento. Quando menos pudiera aqui nombrar más de ciento; y entre todos ellos non ay cosa que enteramente me agrade." ${ }^{2}$

A releitura da lenda de Hero e Leandro pelos quinhentistas ibéricos nos assinala dois aspectos caracterizadores da imitatio e do Renascimento: a leitura crítica dos temas da tradição greco-latina, cuja finalidade era uma melhor compreensão do presente histórico, os Tempos Modernos, e a construção de um ponto de vista individual, cujo resultado foi a redescoberta da subjetividade.

Convém de início relembrar a lenda de Leandro e Hero:

Leandro era um jovem de Abido, amante de uma sacerdotiza de Afrodite, chamada Hero, que vivia em Sesto, a cidade situada na outra margem do Helesponto, em frente a Abido. Todas as noites ele atravessava o estreito a nado, guiado por uma luz que Hero acendia no cimo da torre da casa em que morava. Mas numa noite de tempestade a luz apagou-se e Leandro, envolto pelas trevas, não conseguiu alcançar a costa. No dia seguinte o mar devolveu o seu cadáver, depositando-o junto à torre de Hero. Não querendo sobreviver ao seu amante, ela precipitou-se no mar. ${ }^{3}$

Esta lenda teve por cultores poetas latinos como Ovídio e Virgílio; é, no entanto, do epigrama de Marcial que procedem as glosas quinhentistas de Garcilaso de la Vega, Camões e Sá de Miranda. ${ }^{4}$

O objetivo desta leitura é comparar as diferentes versões quinhentistas, privilegiando (1) a recriação do diálogo entre Leandro

${ }^{1}$ VASCONCELOS, 1934, p.135.

${ }^{2}$ GARCIA, 1984, p.286.

${ }^{3}$ GRIMAL, 1990.

${ }^{4}$ GARCIA, 1984, p.285. 
e o mar - que revela a construção de um ponto de vista lírico para Leandro em sua luta contra as forças da natureza -, (2) as diferentes concepções de Amor que decorrem desse embate e (3) a participação da amada. Antes, citemos o epigrama de Marcial:

Porque a ti, Leandro, as noturnas vagas te pouparam não mais te surpreendas: eram as vagas de César.

Como seus doces amores o audaz Leandro demandasse e, exausto, já as revoltas águas o esmagassem.

diz-se que o infeliz assim as temíveis vagas invocou: "poupai-me nesta ida, afundai-me no regresso. ${ }^{5}$

Entre os gregos, o epigrama era qualquer inscrição num templo ou num túmulo. Por analogia, a palavra passou a designar composições poéticas breves, precisas e agudas, sobre um único assunto. "Entre os romanos, Marcial transforma o epigrama em auxiliar da satyra". 6 "Foram os romanos que [...] imprimiram caráter mordaz ao epigrama, vazando nesta forma, de preferência, ao lado dos temas eróticos, os seus versos satíricos". ${ }^{7}$ Marcial produz uma versão irreverente da lenda do herói de Abido, matriz das versões quinhentistas.

O poeta hispano-romano se notabilizou por sua dicção satírica. Para Menendez y Pelayo, "no hay inclinación perversa de la naturaleza humana caída, no hay bestialidad de la carne que el poeta bilbilitano no haya convertido en materia de chistes, exhibición de torpezas, inmenso periódico satírico". ${ }^{8}$ O mesmo estudioso ressalta que Marcial "trató con desdén a los poetas graves y severos, autores de epopeyas y tragedias". 9 Marcial "llega a burlarse de los grandes mitos consagrados ya por la poesia: Edipo Scila, el robo de Hilas,

${ }^{5}$ GARCIA, 1984, p.285.

${ }^{6}$ BILAC, 1926.

7 COELHO, 1982.

${ }^{8}$ MENÉNDEZ Y PELAYO, 1946,p.285 -290.

${ }^{9}$ MENÉNDEZ Y PELAYO, 1946,p. 287. 
Hermafrodito, Atis... Todo lo encuentra viejo, ininteligibile y agotado". ${ }^{10}$ Menendez y Pelayo tem em mente um epigrama de Marcial que conhecemos pela tradução de Ernesto Cardenal:

Los que leéis macabras historias de Edipo y Tiestes, y Cólquidas, y Escilas, y sólo cuentos de horror: qué interés encontráis en el rapto de Hilas, o en Patenópeo, o Atis, o el Durmiente Endimión, o Hermafrodita indiferente al Agua enamorada? Por qué gozáis con viejas chismografías mitológicas? Leed esto que la Vida puede reclamar como suyo. Aqui no hay ni Centauros, ni Gorgona, ni Harpías. Mi poesía está hecha de seres humanos Pero tú no quieres conocer la vida, Mamurra, ni conocerte a ti. Lee los Origenes de Calímaco. ${ }^{11}$

A lenda de Leandro e Hero parece não ter escapado à sátira do poeta hispano-romano, à sua visão crítica do mito greco-romano. Marcial viveu na primeira centúria de nossa era. Para ele, a mitologia greco-latina assume um sentido bastante diferente do que assumirá para os poetas do Renascimento. Para estes, a Antigüidade grecolatina se ergue como modelo a ser emulado e não como tradição a ser desdenhada. Ao intercalar, em seu epigrama, uma suposta invocação de Leandro ao mar bravio, acaba transformando o trágico desfecho da lenda em matéria para chiste.

A referência quinhentista feita ao epigrama latino é constatada mais pela recriação da invocação final às ondas do mar - que aparece nas três versões, de modos distintos - do que pela manutenção da nota de humor, que não sobrevive nem no soneto de Garcilaso de la Vega. Os três quinhentistas ibéricos lêem a lenda dentro de uma visão trágica, e não irônica, do mundo. Sá de Miranda também dedicou ao tema uma esparsa que ressalta uma outra face da forma epigramática, a face reflexiva, em que se questiona a "bula"

\footnotetext{
${ }^{10}$ MENÉNDEZ Y PELAYO, 1946,p. 288.

${ }^{11}$ CARDENAL, 1978, p.5.
} 
(prescrição) do amor clássico, em contraste com a concepção cristã, apontando-se a ineficácia da bula que prescreve amores malfadados como os de Leandro e Hero.

A versão do poeta espanhol é a mais próxima da de Marcial, mantendo um mesmo conteúdo para a "fala" do amante lendário. O soneto de Garcilaso é:

Pasando el mar Leandro el animoso, en amoroso fuego todo ardiendo, esforzó el viento, y fuése embraveciendo el agua con un ímpeto furioso.

Vencido del trabajo presuroso, contrastar a las ondas no pudiendo, y más del bien que allí perdía muriendo que de su propia vida congojoso, como pudo 'sforzó su voz cansada y a las ondas habló d'esta manera, mas nunca fue su voz dellas oída:

Ondas, pues no se escusa que yo muera, dejadme allá llegar, y a la tornada vuestro furor esecutá en mi vida. ${ }^{12}$

Segundo Rafael Lapesa, Camões, Sá de Miranda e uma constelação de poetas neolatinos teriam imitado a atitude de Garcilaso, glosando também a lenda de Leandro e Hero, a partir do epigrama de Marcial. Para este crítico, a "paráfrase" do epigrama de Marcial é um dos piores sonetos de Garcilaso. ${ }^{13}$

No soneto de Garcilaso, constrói-se uma visão heróica do amante de Abido. No embate com as ondas do mar é exaltado seu ânimo, mas logo ele reconhece não poder resistir a elas, e, numa visão idealizada do Amor, mais preocupado com o bem que perderia

${ }^{12}$ GARCILASO, 1980, p. 27.

${ }^{13}$ LAPESA, 1985, p.164. 
do que com a própria morte, implora às ondas - em vão! - que lhe dêem mais tempo de vida, para que ainda possa encontrar a amada pela última vez... O Leandro de Garcilaso tenta acalmar a fúria das águas, dando em troca a palavra de honra de que voltaria para morrer no mar, o que o Leandro de Marcial jamais faria, sendo este o chiste de seu epigrama. Dentro do código amoroso do cavalheiro, o último apelo deste herói não tem o tom salgado do epigrama de Marcial, e sim um tom franco, nobre, leal.

O foco da relação amorosa está em Leandro, "en amoroso fuego todo ardiendo". Hero só tem sua existência inferida no segundo quarteto como concorrendo para "el bien que allí perdiera muriendo". A rigor aí é referida a relação amorosa, a prática do Amor é o bem referido, que inclui, por lógica, a amada.

Na versão de Camões, não há distanciamento humorístico ou heróico; há, sim, um devotamento religioso à amada. Desloca-se a imagem do fogo da paixão para o da lanterna acesa de Hero, referindo-se ao papel de guia a ela atribuído pela lenda:

Seguia aquele fogo, que o guiava, Leandro, contra o mar e contra o vento; as forças lhe faltavam já e o alento; Amor lhas refazia e renovava.

Depois que viu que a alma lhe faltava, Não esmorece; mas, no pensamento, - Que a língua já não pode - seu intento ao mar, que lho cumprisse, encomendava.

- Ó mar - dezia o moço só consigo -, já te não peço a vida; só queria que a de Hero me salves; não me veja...

Este meu corpo morto, lá o desvia daquela torre. Sê-me nisto amigo, pois no meu maior bem me houveste enveja! $!^{14}$

${ }^{14}$ CAMÕES, 1980, p.118. 
O soneto de Camões também não é considerado dos seus melhores, nem por Faria e Sousa: "que si bien está limpio, no es de los mejores suyos". ${ }^{15}$

O Leandro de Camões é o que se inscreve mais fundamente no código da lírica amatória, nomeando a amada de Leandro, Hero. A invocação ao mar, embora assumida em estilo direto, limita-se à subjetividade de Leandro, que, já sem voz, em pensamento, lhe pede que poupe Hero de ver-lhe o corpo morto. Não pede ao mar que lhe prolongue a vida, aceita a vitória das ondas e, cansado de lutar, não esmorece, e (como o de Garcilaso) exige algo em troca. Aqui o herói é mais generoso do que lá, pois o que o preocupa é o bem de Hero. Esta mesura em poupar o sofrimento da dama é recorrente na lírica cortês de Camões, que se centra na figura feminina e no sofrimento do poeta diante da perda irreparável do objeto amado. Dentro do enredo lírico de Camões, existe, em potencial, um paralelo entre o afogamento de Leandro e o de Dinamene. O poeta, que perdeu a sua "alma" afogada, conhece bem essa dor, que transfunde a Leandro. A relação entre as forças da Natureza e as do Homem são personalizadas, e apesar da inveja (Camões também é alvo da inveja de Amor e da Fortuna) das forças marítmas, Leandro busca abrandar-lhes a fúria, não para salvar-se, mas para que Hero seja poupada.

A esparsa mirandina, por sua vez, também nomeia Hero. Sá de Miranda expressa uma visão crítica da lírica amatória quinhentista: ora, no soneto, tragicamente afirma a vontade do Homem contra as forças da Natureza, ora, na esparsa, ironicamente salienta a falência da bula de amor que só perdoa a culpa, mas não "a dor" e "a pena", acabando por afastar a experiência do amor e do intercurso com a amada. Vejamos o soneto "A la Muerte de Leandro" e, em seguida, a esparsa a uma obra intitulada "Bula de Amor".

${ }^{15}$ GARCIA, 1984 , p. 286. 
Entre Sesto y Abido, al mar estrecho, lidiando con las ondas sin sosiego, noch'alta el buen Leandro prueva el fuego y lágrimas que corren sin provecho.

Viendo qu'es todo en vano, buelve el pecho de nuevo a aquel mar bravo, ojos al fuego, que luze en l'alta torre (Ay! amor ciego, que tanta crueldad has visto y has hecho!)

Nadava, mientras pudo, hacia la playa de Sesto, deseado y dulce puerto, por que siquiera allí muriendo caya.

- En fin, ondas, venceis (dixo, cubierto ya dellas); mas no hareis que allá no vaya: bivo no quereis vos, mas iré muerto! ${ }^{16}$

O soneto luso-castelhano de Sá de Miranda sobre este tema foi considerado excelente por Almeida Garrett que o não seleciona apenas por ser escrito em espanhol: "Sá de Miranda escreveu [...] vários sonetos geralmente de pouca monta. Um d'eles à morte de Leandro e Hero é excelente, mas castelhano, e por esse achaque o não incluí na escolha." 17

A imagem do fogo aqui é bissêmica: serve para caracterizar o desejo do amante, que o prova em seu corpo, e o lugar da amada, a lanterna acesa de Hero, para onde se dirigem o fogo e as lágrimas de Leandro. O soneto espanhol de Sá de Miranda também focaliza Leandro, mas, através de mudanças no tempo verbal - presente nos quartetos, e passado no primeiro terceto - e pela intervenção do ponto de vista do poeta, entre parênteses (prodedimento comum da sua poética reflexiva), revela um distanciamento entre este e o herói da lenda, a imprimir uma visão crítica do amor cego, o Amor, autor de tanta crueldade.

${ }^{16}$ SÁ DE MIRANDA, 1976, p. 298.

${ }^{17}$ GARCIA, 1984, p.100. 
A interpelação ao mar assume um tom trágico no enfrentamento das forças da Natureza, assumindo voluntariosamente a perspectiva renascentista: no embate com as ondas do mar, a vontade do Homem se cumpre ao preço da morte. Ao invocar o mar, Leandro não o faz só em pensamento, nem sem esperança de ser ouvido pelas ondas; mesmo coberto delas, recusa a vitória da Natureza, que não o impedirá de chegar morto à praia de Sesto.

Se, no soneto, Hero está presente através do fogo da lanterna, na esparsa, certa concepção do amor e a própria Hero serão referidas, não sem certa ironia, que contrasta com o tom trágico do soneto em espanhol, mas se aproxima do tom irônico do epigrama de Marcial. A esparsa leva o título: "A uma obra intitulada "Bula de Amor":
A vossa bula de amor não é para toda gente: perdoa a culpa somente, a pena não, nem a dor. E assi faz amor com' ela: que, com esperança incerta, traz ò mar e morte certa Leandro, e Hero à janela; assi que de amor e dela mais se abarca que se aperta. ${ }^{18}$

A bula de amor que não perdoa a dor e a pena serve para os amores trágicos de Leandro e Hero, mas "não é pera toda gente". Quem concebe o amor com essa bula, pode muito abarcar do Amor e do próprio fazer de bulas de amor, mas nunca os aperta, sendo sempre um esforço fadado ao insucesso. Este verso retoma um outro de Petrarca: "e nulla stringo, e tutto " 1 mondo abbraccio". ${ }^{19}$ Provavelmente, o famoso verso de Camões "O mundo inteiro abarco e nada aperto" teve como fonte tanto a esparsa mirandina como o

${ }^{18}$ SÁ DE MIRANDA, 1976, p. 57.

${ }^{19}$ PETRARCA, 1993, p.32. 
soneto de Petrarca, sendo uma leitura indireta dos tempos enfrentados pela cultura portuguesa que o mundo inteiro abarcara sem nada apertar. A esparsa mirandina assume um tom irônico diante dos exageros inúteis prescritos para o amor, e, em medida velha, no seu estilo rústico e conciso, marca a diferença de sua perspectiva poética, centrada numa reflexão sobre as concepções do amor e sobre a individualidade do Homem.

Dos três sonetos quinhentistas, o de Sá de Miranda é o único que não tenta alterar a lenda de Leandro e Hero, através da invocação ao mar, imitada de Marcial. Recicla no verso 10, "De Sesto deseado e dulce puerto", porém, outra imagem do epigrama latino, a dos "doces amores do audaz Leandro" (dulces audax Leandros amores $^{20}$ ). No verso de Miranda o "doce porto" é bissêmico, encerrando dois sentidos: o desejo de chegar à praia de Sesto e o desejo em que arde por Hero.

Nessas versões quinhentistas da fábula antiga, recriando-se a invocação de Leandro ao mar, proposta pelo epigrama de Marcial, parece importar tanto o confronto renascentista entre o Homem e as forças da natureza, como a afirmação da individualidade da perspectiva lírico-amorosa. Com estas construções do ponto de vista de Leandro, os poetas quinhentistas, cada um a seu modo, deixam transparecer uma aproximação com a sua visão lírica particular. Garcilaso, o poeta cavalheiro que empenha ingenuamente a sua palavra; Camões, o amante cortês preocupado em poupar a amada da dor de ver o corpo amado afogado no mar; Sá de Miranda, o moralista que confia no poder da vontade do Homem, que, tendo de ceder à força das ondas, ainda as desafia - em parte as vencerá, como diz no fecho do soneto. E na esparsa, abertamente questiona a validade dessa bula de amor que "com esperança incerta / traz ò mar e morte certa / Leandro, e Hero à janela”. Não se pode deixar de salientar a diferença fundamental entre a sátira de Marcial à

${ }^{20}$ GARCIA, 1984, p. 286. 
cultura greco-latina e a emulação desta mesma cultura pelos poetas quinhentistas, que a elegem como modelo.

\section{2- "As aves todas cantavam d'amores" - ritmo e imagem medievais $\mathrm{n}$ "O sol é grande..."}

As novas formas e o novo ritmo italianos foram introduzidos na poesia ibérica a partir de um respeito à tradição peninsular. Isso gerou o fenômeno do bibridismo poético: formas renascentistas foram compostas com o ritmo medieval ibérico; temas humanistas circularam através de cantigas, vilancetes ou esparsas. Sá de Miranda, o poeta que introduziu o cultivo das formas italianas na língua portuguesa, no primeiro terceto de seu mais afortunado soneto, "O sol é grande...", faz uma referência à poesia medieval galegoportuguesa, através da releitura da imagem do canto das aves e da permanência do ritmo anapéstico.

Eu vira já aqui sombras, vira flores, vi tantas águas, vi tanta verdura, as aves todas cantavam d'amores. ${ }^{21}$

Aqui há uma complexa viagem do poeta ao passado, pela memória de sensações - visão nos dois primeiros versos e audição no terceiro. A visão, apesar de repetida, não tem o seu sentido enfraquecido, pois é figuradora de duas perspectivas diferentes trazidas pela diferença aspectual entre "vira" e "vi". A forma verbal do mais-que-perfeito traduz uma situação em que o sujeito remonta ao passado anterior ao passado, um passado remoto, mais do que extinto: as sombras e as flores pertencem a esse passado longínquo. A forma do pretérito perfeito "vi" refere-se a um passado próximo. No v. 10, o do meio do terceto, parece que o poeta se coloca entre o presente e o passado mais-que-perfeito, aproximando-se, em sua recordação, desse passado remoto, o qual passa a ser referido como

${ }^{21}$ SÁ DE MIRANDA, 1976, p.301. 
um passado mais próximo na memória do poeta. A proximidade aumenta com o uso do imperfeito no último verso do terceto: também o sentido da percepção referido pelo poeta ajuda na aproximação, passa a ser a audição: "As aves todas cantavam d'amores". O aspecto imperfeito sugere uma duração da ação que, no passado, se prolongou por um certo período de tempo. Este período em que o poeta ouvia o canto dos pássaros é recordado como se, através da lembrança, o passado retornasse.

No terceto acima citado, a imagem e o ritmo presentes no verso "As aves todas cantavam d'amores" remetem diretamente para a tradição medieval galego-portuguesa. A imagem das "aves que cantam" está nas cantigas de pelo menos quatro trovadores: Nuno Fernandes Torneol, Airas Nunes, Joan Airas de Santiago e Afonso X.

"As aves todas cantavam d'amores" tem o ritmo anapéstico, ${ }^{22}$ o decassílabo com acentuação na quarta, sétima e décima sílabas. O decassílabo anapéstico pode ser alcançado por uma variação do verso de arte-maior. Este ritmo é comum nos cancioneiros quatrocentistas e galego-portugueses. A tradição palaciana, na busca pelo ritmo toscano, primeiro experimentou com o verso longo da tradição galego-portuguesa. Dependendo do tipo de acentuação de cada um de seus hemistíquios, o verso de arte-maior varia o número de sílabas, mas o ritmo se mantém constante, pois é sempre acentuado na quarta ou quinta sílabas. Quando é composto de dois hemistíquios oxítonos, ele se assemelha ao decassílabo anapéstico.

$\mathrm{Na}$ tradição galego-portuguesa, a imagem das "aves que cantam" assume diversas configurações rítmicas e estróficas, sintetizadas pelo verso mirandino.

Em Nuno Fernandes Torneol, na alba paralelística, "Levad', amigo, que dormides las manhãas frias", ela aparece logo na segunda cobra, num verso de arte-maior:

${ }^{22}$ PIMPÃO, 1972, p.181-182. Este estudo foi publicado pela primeira vez em 1938 na Revista Biblos. 
Levad', amigo, que dormide'-las frias manhãas;

Todalas aves do mundo d'amor cantavan:

leda m'and'eu. ${ }^{23}$

Na cantiga de Airas Nunes, a imagem integral do canto da ave aparece num decassílabo que pode ser lido com o mesmo ritmo do verso mirandino: "e polas aves que cantam d'amores". Esta cantiga de mestria e com finda vale a pena ser citada não só porque comporta relações óbvias com a cantiga de Nuno Fernandes Torneol (agora o namorado "and[a] led' e sem cuidado") e com o afortunado soneto mirandino (através da referência às estações do ano: "O sol é grande caem coa calma as aves / do tempo em tal sazão que sói ser fria”), mas sobretudo por tratar-se de uma cantiga de arte-poética, que associa o cantar das aves ao cantar do trovador:

Que muito m'eu pago deste verão, por estes ramos e por estas flores e polas aves que cantan d'amores, por que ando i led' e sen cuidado e assi faz tod'ome namorado, sempre' i anda led'e mui loução.

Quand'eu passo per alguas ribeiras, so bõas arvores, per bõos prados, se cantan i passaros namorados logu'eu con amores i vou cantando e log'ali d'amores vou trobando e faço cantares en mil maneiras.

Ei eu gran viç[o] e grand'alegria, quando mi as aves cantan no estio. ${ }^{24}$

O cantar das aves relaciona-se ao trovar de amores. O trovador imita as aves e canta de amor. A culta lira mirandina, seja em Alexo ou em Encantamento, seja em outros passos de sua obra, considera

\footnotetext{
${ }^{23}$ SILVEIRA, 1993, p.17.

${ }^{24}$ CORREIA, 1978, p.206.
} 
a escrita a partir dos desmandos da paixão loucura sem cura. $\mathrm{Na}$ cantiga de Airas Nunes, pagar-se quer dizer satisfazer-se, ${ }^{25}$ logo, o trovador está feliz em imitar as aves e o faz "logo ali", isto é, aproveitando a inspiração do canto das aves. No terceto mirandino, esta situação idílica se repete, referindo-se a um passado remoto em relação ao presente de "O sol é grande...", isto é, fazendo uma referência imagética e rítmica à poesia galego-portuguesa, resumida no canto das aves. No presente de "O sol é grande..." as aves "caem coa calma", isto é morrem com o excessivo calor. Em outras palavras, o canto de amor das aves é questionado no presente do soneto em que as aves morrem. O terceto em que aparece o verso de ritmo anapéstico, "As aves todas cantavam de amores", refere-se a um passado remoto idílico até mesmo na opção rítmica.

Joan Airas de Santiago, por sua vez, também usa a imagem do canto das aves, na pastorela "Pelo souto de Crexente". Ela aparece repartida pelos versos da segunda cobra:

$\mathrm{E}$ as aves que voavan, quando saía l'alvor, todas d'amores cantavan pelos ramos d'arredor, mais non sei tal qu'i'stevesse que en al cuidar podesse senon todo en amor. ${ }^{26}$

A imagem aparece em dois versos de redondilha maior, intermediados pela imagem da alba, que também remete para o universo da lírica amatória, em que se fecha a pastorela: não sei quem lá estivesse que pudesse cuidar em outra coisa senão no amor. A exclusividade do tema do amor e a entrega do sujeito ao cuidado amoroso são questões debatidas na obra mirandina. O poeta se coloca num outro espaço mais reflexivo, por exemplo, em algumas éclogas como Basto e Montano, escritas em português, e em que são

${ }^{25}$ CARVALHO, 1939.
${ }^{26}$ SPINA, 1991, p.339. 
debatidas questões filosóficas e poéticas. O próprio "O sol é grande..." é uma reflexão sobre a mudança. Na dedicatória de Montano a João Roiz de Sá de Meneses, a quem Sá de Miranda quer por juiz (não da medida velha!) da questão apresentada no debate da écloga, a opção por um tema estranho à lírica amatória é claramente exposta na recusa do "queixume amoroso":
Mas tornemos aos pastores
que vos querem por juiz;
deixemos de cantar dores;
vereis o que cada um diz;
mas não se queixam d'amores... ${ }^{27}$

Por fim, ainda se pode encontrar a imagem do canto da ave em mais uma cantiga de Afonso X: "Nam me posso pagar tanto". Considerada a melhor cantiga do rei sábio e mesmo de toda a lírica galego-portuguesa, ${ }^{28}$ é difícil a sua classificação dentro das regras trovadorescas, pois propõe novos temas e novas soluções formais para o canto. Ao contrário de Airas Nunes, que muito se pagava, se comprazia, do verão, o rei sábio, como Sá de Miranda, não se pode pagar tanto do canto de amor das aves:

\footnotetext{
Nom me posso pagar tanto do canto das aves nem de seu som, nem d'amor nem d'ambiçom nem d'armas - ca ei espanto, por quanto mui perig[o]sas som, - come dum bom galeom, que me alongue muit' aginha d' este demo da campinha, u os alacrães som; ca dentro no coraçom senti deles a espinha! ${ }^{29}$
}

\footnotetext{
27 SÁ DE MIRANDA, 1976, p. 270.

${ }^{28}$ GONÇALVES, 1983. p.193-195.

${ }^{29}$ GONÇALVES, 1983, p.194-195.
} 
O sujeito, ferido com o espinho do lacrau, não se contenta nem com o canto do amor nem com o uso das armas, e busca uma redefinição da sua identidade, que, curiosamente, se fará através dos signos da navegação e do comércio:

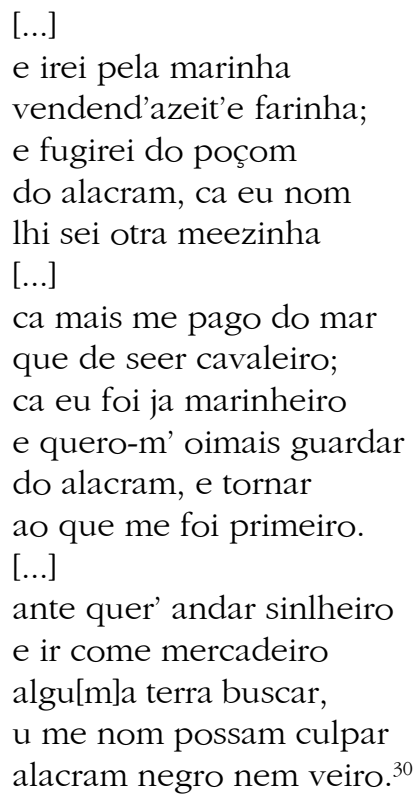

Séculos antes do início da aventura marítima, a navegação e o comércio surgem como identificadores tradicionais da cultura galego-portuguesa. Apesar do poeta quinhentista não engrossar as fileiras dos fascinados pelo mar, a relação entre Sá de Miranda e a poesia galego-portuguesa é profunda e transparece quer nas pesquisas rítmicas quer na circulação de uma única imagem para a metáfora do ato poético: o canto das aves - ainda que ela seja lida de forma a veicular uma concepção diferente do poético. Em "Nom me posso pagar tanto", percebem-se outras afinidades entre Sá de Miranda e o Rei Sábio, como o gosto pela pesquisa com as formas

${ }^{30}$ GONÇALVES, 1983, p. 194. 
e os ritmos poéticos. Há uma insatisfação semelhante que os afasta dos temas comuns. A recusa da lírica amatória aproxima a cantiga do presente referido pelo soneto mirandino em que as aves caem com o calor. No soneto mirandino a mudança faz com que tudo seja vão, na cantiga de Afonso X a mudança é uma oportunidade de redefinição de valores.

Na obra mirandina, há referências explícitas ao trovadorismo galego-português, através do elogio dos reis trovadores, Sancho e Dinis:
A nossa gente que quis arremedar nos louvores, que agora parecem vis, aos bons reis Sancho e Dinis, chamaram-lhes lavradores. ${ }^{31}$

Esses dois reis portugueses incrementaram a economia agrícola e foram trovadores, lavraram terras e trovas. O trovadorismo galego-português teve início no reinado de D. Sancho I e fim no de D.Dinis.

A tradição galego-portuguesa é revisitada pelos poetas quinhentistas como uma fonte antiga peninsular, cujas formas poderiam se prestar a uma reflexão humanística. Por exemplo: a cantiga de amigo de Bernardim Ribeiro "Quando vou aos curraes", editada por Helder Macedo, ${ }^{32}$ versa sobre o tema da vontade amorosa, do ponto de vista feminino.

O discípulo mirandino, António Ferreira, toma o caminho inverso ao de Bernardim: usa a língua galego-portuguesa para compor dois sonetos ("Bom Vasco de Lobeira e de grã sem" e "Vinha amor pelo campo trebelhando"). ${ }^{33}$ A herança galego-portuguesa,

${ }^{31}$ SÁ DE MIRANDA, 1977, p. 93.

32 MACEDO, 1991, p.620.

33 FERREIRA, 1939, p. 95-97. 
presente na escola bernardiniana, também se desenvolve em alguns poetas da escola mirandina. Esta põe em circulação um novo modo de composição (o labor-limae) e uma nova concepção do poético fundada na figura do poeta como leitor de obras antigas da tradição greco-latina e da tradição trovadoresca.

\section{Referências Bibliográficas}

BILAC, Olavo. Tratado de Versificação. Rio de Janeiro: Francisco Alves, 1926.

CAMÕES, Luís Vaz de. Lírica Completa II. Prefácio e notas de Maria de Lurdes Saraiva. Lisboa: INCM, 1980.

CARDENAL, Ernesto. Catulo - Marcial en versión de -. Barcelona: Laia, 1978.

CARVALHO, Carlota Almeida de. Glossário das Poesias de Sá de Miranda. Lisboa: Centro de Estudos Filológicos, 1939.

COELHO, Jacinto do Prado, dir. Dicionário de Literatura. 3a ed. Porto: Figueirinhas, 1982, 5 vols.

CORREIA, Natália. Cantares dos trovadores galego-portugueses. Lisboa: Estampa, 1978.

FERREIRA, António. Poemas Lusitanos. Lisboa: Sá da Costa, 1939/1940. 2 vols.

GARCIA, Alexandre M. Poesia de Sá de Miranda. Lisboa: Comunica-ção, 1984.

GARCILASO DE LA VEGA, Poesias Completas. Madrid: Alianza, 1980.

GRIMAL, Pierre. Dictionary of Classical Mythology. London: Penguin, 1990.

GONÇALVES, Elsa. A lírica galego-portuguesa. Lisboa: Comunicação, 1983.

LAPESA, Rafael. La trayectoria poética de Garcilaso. Madrid: Alianza, 1985. 
MACEDO, Helder. "Sá de Miranda, Bernardim Ribeiro e a escola bernardiniana”. In: Estudos Portugueses. Hom. a Luciana Stegagno Picchio. Lisboa: Difel, 1991.

MENËNDEZ Y PELAYO, M. Historia de las ideas estéticas en España. Vol. 1. Santande: Aldus, 1946.

PETRARCA, Francesco. I POETI ITALIANI / 2 . Supplemento al numero odierno dell' Unità. Roma: Edizione fuori commercio, 1993.

PIMPÃO, Álvaro Júlio da Costa. "O soneto O sol é grande... ". In:-. Escritos Diversos. Coimbra: Coimbra, 1972.

SÁ DE MIRANDA, Francisco de. Obras Completas. 3a ed. introdução e notas de Rodrigues Lapa. Lisboa: Sá da Costa, 1976/1977. 2 vols.

SILVEIRA, Jorge Fernandes da, coord. Antologia da poesia portuguesa. Linhas Mestras * Idade Media. Rio de Janeiro: Faculdade de Letras - UFRJ, 1993. Tom.1.

SPINA, Segismundo. A lírica trovadoresca. São Paulo: Edusp, 1991.

VASCONCELOS, Carolina Michaëlis de. Romances Velhos em Portugal. Coimbra: Imprensa da Universidade, 1934.

\section{Resumo}

A concepção renascentista de criação poética levou não só à imitação dos modelos greco-latinos, mas também à reinterpretação da herança trovadoresca. Este trabalho apresenta, através de dois estudos comparativos centrados em Sá de Miranda, as duas facetas do Renascimento português em sua releitura do passado literário.

\section{Abstract}

Renaissance's poetic conception reclaimed not only imitation of ancient Greek \& Roman models, but also reinterpretation of medieval tradition. This text contains, in two comparative studies around Sá de Miranda, both sides of Portuguese Renaissance's reading of the literary past. 